\title{
Desafios e Dificuldades do Professor Alfabetizador
}

\author{
Maria José Lopes de Sousa Morais ${ }^{1}$; Theóphilo Michel Álvares Cabral Beserra ${ }^{2}$
}

\begin{abstract}
Resumo: Este trabalho teve como objetivo analisar e discutir questões que permeiam o dia a dia escolar do professor alfabetizador, com ênfase nas dificuldades enfrentadas em sala de aula por esse profissional, já que muitas vezes o mesmo depara-se com obstáculos que limitam o seu trabalho e retardam o processo de ensino aprendizagem dos alunos. Realizou-se aqui uma pesquisa bibliográfica para considerar suas contribuições teóricas de diversos autores. Pode-se constatar que alguns dos desafios e dificuldades enfrentados pelo professor são a pouca formação focada na alfabetização, a falta de participação dos pais na vida escolar dos filhos e o alto índice de indisciplina na sala de aula. Diante desses resultados concluiu-se que para superar as dificuldades, o professor deve agir em conjunto com a comunidade escolar e pais para rever Ações e criar outras buscando oferecer uma educação de qualidade ao aluno.
\end{abstract}

Palavras-chave: Professor, alfabetizador, aluno, sala de aula.

\section{Challenges and Difficulties Professor literacy}

Abstract: This study aimed to analyze and discuss issues that permeate the day school day literacy teacher, emphasizing the difficulties faced in the classroom for this professional, since often they are faced with obstacles that limit their work and slow the process of teaching students' learning. It was held here a literature search to consider their theoretical contributions of several authors. It can be seen that some of the challenges and difficulties faced by the teacher are little focused training in literacy, lack of parental involvement in the school life of children and the high rate of indiscipline in the classroom. From these results it was concluded that to overcome the difficulties, the teacher must act together with the school community and parents to review actions and create other seeking to offer a quality education to students.

Keywords: teacher, literacy, student, classroom

\section{Introdução}

Este trabalho tem como papel principal analisar as dificuldades encontradas pelo professor alfabetizador em sala de aula, já que nos dias atuais a nossa sociedade tem atribuído ao professor a responsabilidade de sanar todas as carências intelectuais, corporais, emocionais e sociais dos alunos, além de evitar que os mesmos sejam futuros analfabetos funcionais.

\footnotetext{
${ }^{1}$ Pedagoga pela Universidade Regional do Cariri. Orientadora educacional e professora na escola Padre Cícero. Mestranda em Educação pela Anne Sullivan University;

${ }^{2}$ Licenciado em Geografia pela Universidade Regional do Cariri - URCA, Especialista em Geografia e Meio Ambiente pela URCA, Mestre em Geografia pela Universidade Federal do ceará - UFC. Professor do Instituto Centro de Ensino Tecnológico CENTEC e Professor do Mestrado em Educação da Anne Sullivan University. E-mail: mic.beserra@ hotmail.com.
} 
$\mathrm{Na}$ constante busca por novas práticas e métodos pedagógicos ,o professor tem visto a alfabetização como uma fase distinta, que requer conhecimentos específicos na área.Esta perspectiva, constitui-se questões que norteiam este trabalho, como: quais os desafios que dificultam o fazer pedagógico do professor alfabetizador?; por que o professor alfabetizador se encontra tão preocupado com suas práticas pedagógicas do dia a dia?Falar sobre alfabetização é complexo até pela diversidade de métodos utilizados e devido as dificuldades de aprendizagem dos alunos, reprovações e evasões escolares.Assim a alfabetização caracteriza-se por uma fase muito importante para o desenvolvimento do aluno,considerada a base de todo conhecimento futuro.

Segundo o dicionário Aurélio,alfabetizar é ensinar a ler e escrever ou dar instrução primária.Mas sabemos que alfabetizar vai muito mais além que ensinar a ler e escrever, nesta tarefa a linguagem é uma fiel aliada dos professores neste processo de ensino aprendizagem. A linguagem é uma a'rea muto importante para a aquisição da escrita e leitura,pois dar oportunidade para que o homem estabeleça uma comunicação intersubjetiva,isto é, estabeleça a troca de diálogo. Acontecendo isso, o aluno amplia seu vocabilário e elabora novas hipóteses silábicas.

Estudos afirmam que o sujeito se constitui em dos momentos, o primeiro no social e o segundo no individual numa apropriação ativa e constante.Esse processo acontece na escola de forma contínua,remetendo ao professor um papel importante de mediador do processo de aquisição da escrita e da leitura com intervenções pedagógicas coerentes, já que os conhecimentos resultam da pluralidade de significações e sentidos compartilhados no coletivo,conforme Lemle,

É claro que, além dos conhecimentos básicos, o alfabetizador precisa de outros dons para se sair bem. Ele deve ter respeito pelos alunos, evitar o papel de cúmplice de um sistema interessado em manter esmagada uma grande parte do seu povo, confiar na capacidade de desenvolvimento dos alunos e ter criatividade, inventividade, iniciativa, combatividade e fé em sua capacidade de tornar este mundo melhor. (LEMLE,1988;p.6).

Contudo grandes são os desejos e anseios que o professor alfabetizador tem em favor de uma educação de qualidade e igualitária, que possa oferecer oportunidades para os alunos avançarem rumo ao conhecimento significativo e incluii-los na cultura da escrita e não da 
exclusão.Sendo assim, o professor encontra-se apreensivo diante de tamanha responsabilidade no cenário da educação atual. Perante tantos desafios,é visível a busca dos professores por salas de ensino mais adiantadas do que as salas de alfabetização,sendo que poucos encaram esse desafio e adquirem experiências metodológicas e pedagógicas para enriquecerem o universo da alfabetização.

Este estudo, utilizou-se de metodologia de pesquisa bibliográfica de caráter qualitativo para alcançar seus objetivos. Mediante as revisões bibliográficas , sobre obras que trazem informações e definições relevantes ao desdobramento do trabalho.

Este estudo foi fundamentado nas ideias e concepções de autores como: CAMBI(1999)， FERREIRO(1985)， LEMLE(1988)， NÈRICI(1972)， PIAGET(1977) e POERCH(1990).

\section{A Alfabetização}

A alfabetização é um período distinto , cheio de novas experiências e sensações com as quais os alunos se deparam quando chegam a escola, para aqueles que ainda não frequentavam a educação infantil, torna-se o primeiro contato com a educação formal.Durante muito tempo a alfabetização foi encarada como uma mera aquisição de conhecimento da escrita, ou código escrito, que preparava alguns alunos para as fases seguintes.

Na década de 70 e 80 o elevado número de analfabetismo, de repetência e evasão levaram a uma busca por novas estratégias de conceber e direcionar o trabalho da educação e os conceitos equivocados sobre a alfabetização foram aos poucos superados.

\section{Segundo Cambi(1999),}

A partir dos anos 80 e sucessivamente até hoje, a pedagogia foi atravessada por um feixe de novas emergências, novas exigências e novas formulas educativas, novos sujeitos do processo formativo/educativo e novas orientações políticos culturais. (CAMBI,1999,p.638)

Esses novos momentos foram marcados por pensamentos e reflexões sobre o individuo e como deve ser o ponto de partida para a construção de novos conhecimentos. $\mathrm{O}$ 
Id on Line Revista Multidisciplinar e de Psicoloqia

Id on Line Multidisciplinary Journal and Psycology

quadro da educação teve grandes mudanças devido ao novo modo de se construir conhecimentos, junto com os acontecimentos da atualidade e dando foco as particularidades do aluno.Sendo assim, a alfabetização e a pratica educativa do professor também sofreu influência, onde a utilização de temas atuais e do interesse do aluno passaram a ser relevantes para a sua formação intelectual e social.

Essa mudança na educação se deu também sobre análises dos estudos sobre a psicogênese da aquisição da escrita e com as contribuições de Emilia Ferreiro e Ana Teberosky (1985) enfatizando que a alfabetização se caracterizava como um processo ativo com o qual uma criança em contato com a cultura escrita vai aos poucos construindo hipóteses sobre a língua escrita, até chegar a escrita convencional e não uma mera decodificação e codificação do sistema linguístico.

Há uma visão sobre esse processo radicalmente diferente; no lugar de uma criança que esperava passivamente o reforço externo de uma resposta produzida pouco menos que ao acaso, aparece uma criança que procura ativamente compreender a natureza da linguagem que se fala a sua volta, e que, tratando de compreende-la, formula hipóteses, busca regularidades, coloca a prova suas antecipações e cria sua própria gramática (que não é simples copia deformada do odelo adulto, mas sim criação original,

Utilizando esses estudos o professor alfabetizador passa a ser um mediador desse processo,propondo desafios através de atividades planejadas com uma intencionalidade pedagógica. Deste modo, o aluno passará aos poucos a fazer novas descobertas e construirá suas hipóteses. Por isso o estímulo visual utilizando diferentes gêneros textuais é extremamente importante nessa fase (FERREIRO,1985,p.22).

No período da alfabetização o professor é de extrema importância, porém em algumas situações esse profissional sequer é habilitado para exercer tal função, já que muitos não tiveram formação apropriada ou sequer sabem quais as etapas de um processo de construção da escrita. Sendo assim, como tal profissional poderá conduzir e desenvolver bem esse processo, se não compreende sua importância e como se dá? É urgente a implementação de ações que deem suporte teórico,técnico e profissional para esses profissionais no meio da educação, pois muitos ainda estão" araizados" aos livros didáticos ou aos conteúdos programados por medo de errar ou simplesmente por ser mais cômodo.É urgente e necessário 
mudanças no fazer educativo com foco nas praticas pedagógicas, onde a ação-reflexao-ação, estejam sempre juntas, ou seja onde a teoria esteja sempre ao lado da pratica.

O alfabetizador é um profissional do ensino de línguas e, como tal, além do domínio e das técnicas pedagógicas deve possuir sólidos conhecimentos linguísticos tanto da língua, enquanto meio de comunicação, enquanto objeto de análise. (POERSH,1990,p.37)

Sendo assim, o professor que está em sala de aula tem a obrigação de oferecer uma educação de qualidade e para isso precisa ter formação e competência para desenvolver um trabalho satisfatório.É fato que existe a falta de interesse de alguns professores pela busca de novos conhecimentos, pela busca de novas ferramentas e técnicas pedagógicas em sala de aula para aperfeiçoar seu trabalho.Portanto o professor será o profissional que estimulará as descobertas da língua escrita até que o aluno chegue a escrita convencional.

Além dos desafios encontrados em sala,outro bem pertinente é a falta de acompanhamento e apoio dos pais na vida escolar dos alunos, o professor encontra-se sozinho com a responsabilidade de alfabetizar a qualquer maneira.Um fator importante é que os pais atribuem ao professor o fracasso escolar dos filhos, dando continuidade ao conflito entre família e escola.Alguns pais abandonam de forma revoltante a vida escolar dos filhos e isso se tornam mais requente a cada dia no ambiente escolar,pois muitos alunos vão e voltam com as atividades em branco, chegam totalmente desmotivados a sala de aula e trazem a ideia de que não podem repetir de ano mesmo que não tenham o conhecimento necessário para progredirem, sendo que muitas vezes precisam serem motivados e estimulados exteriormente para que haja construção de aprendizagem e mesmo assim alguns ainda não encontrem.Essa é infelizmente a realidade em algumas salas de aula, pois pais negligentes e omissos, que não se preocupam com a aprendizagem dos filhos, não comparecem as reuniões, não vão a escola quando convocados e não favorecem a interação família e escola.

A legislação tem atribuições bem claras e especificas para a família, o Estado, a constituição federal em seu artigo 205, afirma que " a educação é direito de todos e dever do Estado e da familia”. A educação informal é obrigação da família e a educação formal é dever do Estado, portanto as duas instituições devem estar sempre em constante harmonia e parceria para priorizar uma boa educação e que a mesma seja de qualidade.

Nérici (1972), salienta sobre essa relação que, 
A educação deve orientar a formação do homem para ele poder ser o que é, da melhor forma possível, sem mistificações, sem deformações, em sentido de aceitação social. Assim a ação educativa deve incidir sobre a realidade pessoal do educando, tendo em vista explicitar suas possibilidades, em função das autenticas necessidades das pessoas e da sociedade. (NÉRICI,1972, p.12).

Desta forma, entendemos que a escola e a familia se completam na tarefa de formar socialmente a criança, e que se uma se omite quanto as suas obrigações e atribuições o processo de ensino- aprendizagem fica prejudicado. Nesta perspectiva Nérici (1972) considera que, a influência e a participação da família é fundamental e essencial no processo educativo da criança e que nem uma outra instituição tem condições de substituí-la. Sabemos que muitas vezes o trabalho e a falta de tempo são algumas das justificativas dos pais sobre a ausência, considera-se que essas ausências "desculpas", futuramente não iram sanar as dificuldades e carências intelectuais, afetivas e sociais que poderão ocorrer no aluno.

Outro fator importante e notável em sala para o professor é a indisciplina dos alunos durante as atividades desenvolvias diariamente proposta, a falta de interesse e de otimismo para conquistar uma vida futura e prospera está a cada dia mais distante da realidade dos nossos alunos.Falta interesse, amor e curiosidade na busca de conhecimentos, já que para a maioria dos alunos o estudo é uma atividade fatigante e obrigatória.Uma parcela boa da aula é reservada ou desperdiçada para advertir alunos indisciplinados, que muitas vezes usam termos pejorativos contra o professor e colegas de sala. Nesta perspectiva, podemos perceber que esta ficando mais difícil a cada dia estabelecer regras para organizar as salas e trabalhar com ordem e coerção. Segundo Piaget (1977,p.7) "toda moral é um sistema de regras e a essência de toda moralidade consiste no respeito que o individuo sente por tais regras".

Sendo assim mais uma vez o professor entra em ação na busca constante de meios para fundamentar e estabelecer regras de boa convivência e de respeito mutuo, dando prioridade a formação do cidadão. Por isso cabe ao professor usar dinâmicas eficazes que possibilitem uma boa sintonia entre os aspectos sociais e intelectuais. Esse tipo de tarefa atribuída ao professor educador chama-se interdisciplinaridade, vivenciada na sala de aula na formação humana propostas nos parâmetros curriculares como eixos que considera o aluno em sua totalidade e não como um individuo fragmentado.

Estes são obstáculos e desafios com os quais o professor tem se deparado na sua prática do fazer educativo, causando angústia, desmotivação e sofreres. Que diariamente leva 
a ação- reflexão- ação de sua prática pedagógica na procura de soluções para modificar esse cenário de frustrações que se encontra do contexto da educação. O professor consciente e atuante busca conhecimentos diversificados através de cursos, leituras diversificadas para enriquecer e aperfeiçoar sua atividade educativa.

\section{Conclusão}

Conclui-se perante este estudo que a tarefa do professor é muito difícil e árdua, pelas dificuldades que o mesmo enfrenta diariamente no ambiente escolar,pois é o professor quem irá abrir as portas da leitura e da escrita para o aluno rumo a aprendizagem.O professor segundo alguns estudos teóricos deve oferecer condições ao aluno para que o mesmo possa construir da leitura e da escrita no contexto escolar.

O aluno não deve ser encarado erroneamente como um ser para se depositar informações, ou seja fruto de uma educação bancária e sim incluir praticas educativas com metas para uma educação com sentido de construção não apenas de conhecimentos científicos, mas com significado, com valores e cidadania no ambiente e no dia a dia escolar.A educação faz-se necessária ser repensada dando foco ao relacionamento interpessoal,onde o aluno possa dispor de meios e possibilidades para construir uma aprendizagem significativa.

É imprescindível para se realizar um trabalho satisfatório entre a família e a escola , esquecer a histórica disputa de culpas sobre o fracasso do aluno e buscar a paz através de atitudes conjuntas que busquem reatar o companheirismo e o respeito entre essas duas instituições para aquisição de uma educação de qualidade .

Portanto,ter um ideal de uma educação com objetivos de transformação social é romper com o antigo e ousar com o novo,utilizando-se de meios diversificados conduzindo o aluno a não somente ler e escrever letras, mas saber dar sentido e significado naquilo que está lendo e escrevendo.Entender que o papel do professor não é meramente transferir conteúdos e sim construir e dividir saberes, oferecendo aos alunos que apresentarem dificuldades conhecimentos contextualizados e prazerosos para que se desenvolvam . 
A falta da participação na vida escolar do aluno é outro ponto pertinente nesse estudo, fazendo-se necessário idealizar meios que despertem o interesse por uma relação mais próxima que permita a troca de experiências no ambiente escola e família. Uma boa estratégia para sanar esse distanciamento da família seria o trabalho com projetos interdisciplinares com ênfase na família, convidando os pais para assistirem palestras, participarem de oficinas participarem de ações diversificadas na escola que possam contribuir para o sucesso escolar dos filhos.

A indisciplina e seus grandes índices atualmente na escola também é um ponto aterrorizador e para reverter esse cenário é necessário a prática de ações que busquem sensibilizar o aluno para respeitar normas e regras.

O aluno deverá aprender através dessas regras que, o verdadeiro sentido da cidadania e dos valores morais irão refletir na sua formação ética e social.Neste estudos destacamos alguns obstáculos encontrados pelo professor em sala de aula,para superá-los o professor deve trabalhar em conjunto com a comunidade escolar e com pais para reverter situações indesejadas e criar ações com o objetivo de oferecer uma educação qualitativa ao aluno.

Sabemos que diariamente é atribuído ao professor a responsabilidade de educar o aluno, e lhe é exigido resultados desse trabalho. Entretanto é impossível o professor desenvolver um bom trabalho sozinho, o mesmo necessita de apoio pedagógico e da família. Porém essa árdua tarefa lhe compete também o papel de promover o uso social de textos diversificados para apresentar ao aluno, mostrando significado nas atividades com foco na contextualidae do aluno. Os desafios são importantes para amadurecer e transformar na busca de uma pratica inovadora, são eles que oferecem ao professor meios para construir um melhor fazer escolar .

O professor não deve permitir que os desafios o desmotivem, mas que os mesmos lhe incentivem a uma constante inquietude para estimulá-lo na busca por meios para desenvolver uma pratica significativa e fundamentada teoricamente. Trabalhar com educação requer competência e compromisso com um ensino que vise uma genuína transformação social dos alunos que interagimos diariamente no ambiente escolar. 


\section{Referências}

HOLAMDA, A.B. Mini dicionário da língua portuguesa. $4^{\mathrm{a}}$ edição revista e ampliada do mini-aurélio. $7^{\mathrm{a}}$ impressão - Rio de Janeiro, 2002.

BRASIL, Constituição de 1988. Constituição da Republica Federal do Brasil; promulgada em 5 de Outubro de 1988

CAMBI, Franco. História da pedagogia. Tradução de Álvaro Lorencini. São Paulo: Fundação editora da UNESP, 1999.

FERREIRO, Emilia. Psicogênese da língua escrita. Porto Alegre: Artes médicas, 1985.

LEMLE, Miriam. Guia teórico do alfabetizador. $2^{\text {a }}$ Ed. São Paulo: Ática, 1988.

NÉRICI, Imideo G. Lar, escola e educação. São Paulo: Atlas, 1972.

PIAGET, J. O julgamento moral na criança, São Paulo: Summus, 1977.

POERSH, J. M. Suportes linguísticos para a alfabetização. 2a edição, Porto Alegre: Sagra, 1990.

Como citar este artigo (Formato ABNT):

SOUSA, M.J.L.; BESERRA, T.M.A.C. Desafios e dificuldades so professor alfabetizador. Id on Line Revista Multidisciplinar e de Psicologia, Set-Out de 2016, vol.10, n.31, Supl 2, p. 262-281. ISSN 1981-1179.

Recebido: 26/09/2016

Aceito: 29/09/2016 